\title{
OSVALDO SANGIORGI E O MOVIMENTO DA MATEMÁTICA MODERNA NO BRASIL ${ }^{1}$
}

\author{
Osvaldo Sangiorgi et le mouvement des \\ mathématiques modernes au Brésil
}

Wagner Rodrigues Valente

Professor do Programa de Mestrado em Educação Matemática da Universidade Bandeirante de São Paulo, GHEMAT- UNIBAN, SP; UIED, UNL - São Paulo, SP Brasil, e-mail: wagner.valente@pq.cnpq.br

\section{Resumo}

Este texto analisa a singularidade da recepção no Brasil de propostas internacionais para modificação do ensino de matemática na segunda metade do século XX. Em meio ao que fica conhecido como Movimento da Matemática Moderna MMM, o estudo destaca a participação do professor Osvaldo Sangiorgi nos processos de apropriação de um ideário construído alhures, que promove alterações profundas na matemática escolar das salas de aula brasileiras.

Palavras-chave: Osvaldo Sangiorgi; Movimento da Matemática Moderna; História da educação matemática; Livro didático.

\footnotetext{
1 Uma versão preliminar deste texto foi apresentada no IV Seminário Temático do projeto de cooperação internacional Capes-Grices "A matemática moderna nas escolas do Brasil e de Portugal: estudos históricos comparativos," em Outubro de 2007, em Portugal. O autor fica muito agradecido à leitura crítica do trabalho realizada naquela ocasião pelos professores Luís Saraiva e Jorge Ramos do Ó, ambos da Universidade de Lisboa.
}

Rev. Diálogo Educ., Curitiba, v. 8, n. 25, p. 583-613, set./dez. 2008 


\section{Resumé}

Le text a pour but analyzer les particularités de la présence du Mouvement des Mathématiques Modernes au Brésil. L'étude faire un exposé détaillé du rôle de premier plan du professeur Osvaldo Sangiorgi, auteur de manuels scolaires les plus vendus pendant l'époque du Movement.

Mots-clés: Osvaldo Sangiorgi; Mouvement des mathématiques modernes; Histoire de la éducation mathématique; Manuels scolaires.

\section{Um novo tempo, uma nova matemática escolar}

"Movimento da Matemática Moderna" é a expressão utilizada no âmbito dos estudos sobre o ensino da Matemática, que caracteriza um período em que se elaboram novas referências para o ensino da disciplina. O MMM tem alcance mundial. $\mathrm{O}$ pesquisador Henrique Guimarães, em síntese de vários trabalhos, aborda o início desse Movimento considerando que:

No período do pós-guerra e ao longo dos anos 50, em muitos países da Europa e também em países desenvolvidos do outro lado do Atlântico, muito em particular nos Estados Unidos da América, começou a tomar corpo a idéia de que se tornava necessário e urgente uma reforma no ensino da Matemática. $\mathrm{Na}$ verdade, durante toda a década de 50, foram tendo lugar numerosas iniciativas e realizações, de natureza variada e com propósitos diversificados, que tinham em comum a intenção de modificar os currículos do ensino da Matemática visando a atualização dos temas matemáticos ensinados, bem como a introdução de novas reorganizações curriculares e de novos métodos de ensino. (GUIMARÃES, 2007, p. 21).

Uma das primeiras ações com vistas à reformulação do ensino da Matemática é a criação, em 1950, da CIEAEM - Commission Internationale pour l’Étude et l'Amélioration de l'Enseignement des Mathématiques. É pela iniciativa de Caleb Gattegno, matemático, pedagogo e filósofo da Universidade de Londres, que se reúnem, entre outros, matemáticos como Jean Dieudonné, Gustave Choquet,

Rev. Diálogo Educ., Curitiba, v. 8, n. 25, p. 583-613, set./dez. 2008 
Osvaldo Sangiorgi e o movimento da matemática moderna no Brasil 585

André Lichnerowicz e o psicólogo Jean Piaget. A Comissão é criada com a intenção de "estudar o estado presente e as possibilidades de melhorar a qualidade do ensino e aprendizagem da Matemática." A Matemática é tomada como domínio privilegiado, justifica a Comissão, pois “já existem pesquisadores competentes no domínio dos fundamentos, da lógica, da epistemologia, da história, da psicologia do pensamento e da pedagogia experimental". Assim, a Comissão traz para si a tarefa de "produzir a síntese das contribuições trazidas por essas disciplinas ao objeto principal (o ensino de matemática)" (PIAGET et al., 1955, p. 6).

A primeira contribuição coletiva dessa Comissão materializa-se na obra L'enseignement des mathématiques, que reúne textos de J. Piaget, E. W. Beth, J. Dieudonné, A. Lichnerowicz, G. Choquet e G. Gattegno, publicada em 1955.

O primeiro capítulo da obra é escrito por Piaget: Les structures mathématiques et les structures opératoires de l'intelligence. No texto, o autor aborda o que caracteriza como questão antiga da filosofia ocidental: "saber se as conexões matemáticas são engendradas pela atividade interna da inteligência ou se elas provêm da ação inteligente sobre o mundo exterior" (PIAGET et al., 1955, p. 11). Para Piaget, se a questão é tratada em termos da psicologia genética, há uma renovação do problema, com a contribuição dos matemáticos do grupo Bourbaki, que trazem como papel fundamental, a noção de estrutura. Desse modo, o texto busca precisar em que sentido as estruturas matemáticas fundamentais consideradas pelos matemáticos, correspondem às estruturas elementares da inteligência, sendo as primeiras um prolongamento formalizado e não a expressão direta das segundas (PIAGET et al., 1955, p. 17). Por fim, o estudo de Piaget considera que:

Se o edifício matemático repousa sobre estruturas, que correspondem além do mais às estruturas da inteligência é, então, sobre a organização progressiva dessas estruturas operatórias que é preciso estar baseada a didática matemática. (PIAGET et al., 1955, p. 32).

Isso leva a considerar o antigo problema da filosofia ocidental, fora da dicotomia racionalismo-empirismo ao se levar em conta que:

O recurso à experiência e à ação, e de modo geral à pedagogia dita ativa, entre os procedimentos de iniciação matemática, não comprometem em nada o rigor dedutivo posterior do pensamento matemático, bem ao contrário: o preparam, fornecendo-lhe bases reais e não simplesmente verbais. (PIAGET et al., 1955, p. 33).

2 Informação do sítio da Comissão. Disponível em: <http://www.cieaem.net/CIEAEM9bis/ index_france.htm>. Acesso em: 4 set. 2007.

Rev. Diálogo Educ., Curitiba, v. 8, n. 25, p. 583-613, set./dez. 2008 
O segundo capítulo da obra é escrito por Ewart Beth e tem por título Réflexions sur l'organisation et la méthode de l'enseignement mathématique. Beth aborda o assunto, como ele ressalta, de modo axiomático. Assim, enumera o que identifica como postulados fundamentais sobre o tema:

1. todo instituto de ensino superior tem por objetivo, entre outros, preparar seus alunos - chamados estudantes - a julgar por eles mesmos questões pertencentes a um ou diversos domínios científicos especializados e de aplicar seu julgamento à solução de certos problemas de ordem prática; em particular há institutos que preparam seus estudantes para que julguem por si próprios questões matemáticas e apliquem seu julgamento à solução de problemas suscitados pelo ensino de matemática;

2. todo instituto de ensino secundário tem por objetivo, entre outros, preparar futuros estudantes;

3. os professores do ensino secundário são formados nos institutos de ensino superior;

4. as matemáticas fazem parte do programa normal dos institutos de ensino secundário.

Tais premissas do texto de Beth levam à necessidade de estreita interação entre a matemática do ensino superior e aquela do ensino secundário. Em meio a essa tese, há o desafio pedagógico, as questões relacionadas ao ensino. Como promover essa interação e proximidade dos programas da instância superior e secundária do ensino? Beth mostra-se não convencido plenamente das contribuições trazidas pela psicologia. Mas, dá crédito ao trabalho de Piaget:

A epistemologia genética de Piaget se distingue do psicologismo corrente pelo cuidado, não de adaptar a lógica ao mecanismo real do pensamento, mas pela descrição das diferentes fases do desenvolvimento intelectual por meio das estruturas elaboradas pela lógica moderna. (BETH, 1955, p. 45).

Por outro lado, faz uma ressalva às pesquisas e conclusões do epistemólogo suíço:

A única objeção de princípio que o lógico pode fazer às considerações de Piaget, é que o autor tira de seus resultados argumentos contra certos aportes da pesquisa dos fundamentos. Isso pode ser uma inconsequência que deriva da influência do psicologismo corrente. (BETH, 1955, p. 46).

Rev. Diálogo Educ., Curitiba, v. 8, n. 25, p. 583-613, set./dez. 2008 
Osvaldo Sangiorgi e o movimento da matemática moderna no Brasil 587

Segue-se ao texto de Beth, o estudo do matemático Jean Dieudonné, intitulado L'abstraction en mathématique et l'évolution de l'algèbre, que compõe o capítulo 3 da obra.

Dieudonné inicia seu texto lembrando que desde sempre as matemáticas com a metafísica dividem o caráter de serem domínios do abstrato, longe da realidade concreta da experiência sensível. Em seguida, menciona que na ambiência de ensino, tem havido uma tendência de mascarar esse caráter abstrato das matemáticas. O que considera um grave erro. O autor resguarda-se de ser mal interpretado nessa afirmação, considerando que não é o caso de, logo ao princípio, levar os jovens a concepções muito abstratas, para além daquilo que suas capacidades possam assimilar. Mas, que não deve ser perdido o objetivo de conduzir os estudantes a esse caráter abstrato das matemáticas (DIEUDONNÉ, 1955, p. 41).

Essas considerações iniciais levam Dieudonné ao objetivo de seu texto: defender a essência do que chama "método matemático" no processo de ensino, considerando que as matérias a serem ensinadas como meios para ilustrar esse método. Assim, interroga-se novamente o autor:

Mas, o que trata a essência da matemática, senão o poder de abstrair e de raciocinar sobre noções abstratas? Iremos hesitar em anunciar isso se, como foi dito anteriormente, essa verdade estiver sendo perdida de vista. É por isso, eu creio, que não seja inútil lembrar que os grandes progressos, em matemáticas, estão sempre ligados a um progresso da capacidade de nos lançarmos um pouco mais alto no domínio da abstração. A história da álgebra, desde os seus primeiros passos até nossa "álgebra moderna", ilustrará essa tese nas páginas seguintes. (DIEUDONNÉ, 1955, p. 48).

A seguir, contando a sua história da álgebra moderna, Dieudonné desemboca na importância das estruturas matemáticas, ilustrando o que considera o método matemático e concluindo:

Vemos assim, como o estudo das estruturas pode fornecer ao matemático, utensílios de valor universal. Diante da profusão de publicações matemáticas de toda espécie que sai todos os anos, somente o método axiomático permite canalizar de algum modo as novas descobertas, classificá-las e amalgamá-las aos resultados anteriores [...]. (DIEUDONNÉ, 1955, p. 61).

Rev. Diálogo Educ., Curitiba, v. 8, n. 25, p. 583-613, set./dez. 2008 
Ao capítulo escrito por Dieudonné, segue o capítulo 4, escrito por André Lichnerowicz, Introduction de l'esprit de l'algèbre moderne dans l'algèbre et la géométrie élémentaire. O texto busca resposta para a questão: Em que medida é possível trazer o espírito das matemáticas contemporâneas para o ensino secundário? Essa pergunta o autor formula a partir de sua experiência de formação de professores de matemática para o nível secundário. Nesse sentido, faz um alerta para o fato de que o ensino de matemática nos liceus conduz a uma concepção sobre matemática que não está em acordo com a atualidade matemática. Isso, no entender do autor, leva os alunos a terem um choque ao ingressarem na universidade. A partir dessas observações, Lichnerowicz dá vários exemplos do distanciamento existente entre o ensino secundário e os estudos universitários de matemática. Para o autor, ao retomar a questão de seu texto, a introdução da álgebra moderna deve pautar-se por um ensino que, certamente, não deva inculcar dogmaticamente teorias abstratas, porém, diz ele:

Eu creio simplesmente que através de numerosos exemplos elementares devem-se obter noções fundamentais, de modo a habituar desde o início, os alunos a se familiarizarem-se com as principais estruturas algébricas, que eles manuseiam muito cedo e que os professores não os levam a reconhecer. (LICHNEROWICZ, 1955, p. 66).

A partir dessas considerações, o autor enumera exemplos onde podem ser tratados, de modo elementar, noções como as de: grupo, relação de equivalência, espaço vetorial, dentre outras.

Finalizando seu texto, após os vários exemplos, diz o autor:

Eu creio que não podemos, no ensino elementar, tratar de noções algébricas em grande número, mas é possível fazê-las serem percebidas pelos alunos; e eu penso simplesmente que se o professor tem para si presente o espírito das diferentes noções, as diferentes exigências fundamentais, alguma coisa de essencial acaba passando para o cérebro dos alunos. Algo que os poupará das dificuldades no futuro, pois isso se trata mesmo de um objetivo de nosso ensino: fazer com que os alunos participem da ciência e da tecnologia vivas de nosso tempo. (LICHNEROWICZ, 1955, p. 74).

O penúltimo capítulo do livro é escrito por Gustave Choquet, e tem por título, Sur l'enseignement de la géométrie élémentaire. O autor, desde logo, faz uma crítica ao tratamento dado à geometria pelos livros didáticos:

Rev. Diálogo Educ., Curitiba, v. 8, n. 25, p. 583-613, set./dez. 2008 
Osvaldo Sangiorgi e o movimento da matemática moderna no Brasil 589

É surpreendente constatar como as pesquisas teóricas dos últimos séculos tem pouca influência sobre o ensino da geometria elementar. No momento em que possuímos todos os elementos para a construção de uma exposição coerente e simples, tendo pesquisas como as de Hilbert, completamente elucidado a natureza e o papel dos axiomas de base, os livros didáticos são, no que diz respeito aos fundamentos, inferiores aos "Elementos" que Euclides ensinava há mais de 2000 anos. (CHOQUET, 1955, p. 75).

Apesar da crítica, Choquet faz a ressalva que não considera desejável que seja apresentada aos jovens alunos uma exposição axiomática rigorosa da geometria. E, para ele, a questão pedagógica relativa ao seu ensino deve ser colocada em outro patamar. Será possível, segundo ele, permanecer próximo da experiência sensível do aluno e construir com ele a geometria elementar clássica. Mas, a questão pedagógica principal é fazer com o aluno, a seu tempo, possa ser levado a perceber que a insatisfação com certos axiomas de base, permitam que ele venha a imaginar outros. Desse modo, o aluno:

[...] descobrirá então que se a aplicação de regras do jogo matemático é já para o espírito um agradável exercício, a criação e o exame crítico de novas regras, não somente trazem satisfação de uma nova ordem, mas permitem também, quando ele retorna às regras clássicas, compreender a edificação da geometria com um espírito mais lúcido. (CHOQUET, 1955, p. 76).

Na crítica que faz a seguir ao modo de exposição da geometria pelos manuais didáticos, o autor demonstra como deveria ser apresentada a geometria elementar em termos estruturais.

Finalizando a obra, o livro apresenta o capítulo VI, de autoria de Caleb Gattegno, La Pédagogie des Mathématiques. Gattegno, no primeiro parágrafo de seu texto informa:

Neste capítulo nós trataremos da pedagogia matemática como uma ciência. Isso quer dizer que iremos nos ater aos aspectos da pedagogia dessa disciplina que podem ser comunicáveis a todos e suscetíveis de serem traduzidos em técnicas impessoais. (GATTEGNO, 1955, p. 131).

A questão de Gattegno liga-se, no fundo, a como generalizar atitudes pedagógicas que deverão ser seguidas pelo professor de matemática, face ao paralelo das estruturas mentais dos alunos com as da estruturas matemáticas.

Rev. Diálogo Educ., Curitiba, v. 8, n. 25, p. 583-613, set./dez. 2008 
Assim, ao longo de seu texto, preocupa-se com o modo de encaminhar lições de álgebra e geometria em cada série escolar do ensino secundário.

Em síntese, o livro L'enseignement des mathématiques reúne as preocupações de matemáticos com a aproximação, que julgam imperativas, da matemática elementar com a superior. Essa questão didático-epistemológica ganha cientificidade por meio dos estudos de Jean Piaget e o paralelismo das estruturas cognitivas com as estruturas matemáticas. É possível afirmar que a publicação da obra cria bases para novas discussões em direção a propostas de um currículo moderno para o ensino de matemática. Corrobora essa afirmação a existência de outro marco importante das discussões sobre a mudança da matemática escolar, que ocorre em finais da década de 50, para além da publicação desse livro:

Em 1959, a culminar este interesse muito alargado de modernização do currículo de Matemática, a Organização Européia de Cooperação Econômica (OECE) decidiu realizar um inquérito sobre a situação do ensino dessa disciplina nos seus países membros, bem como uma sessão de trabalho apoiada nos resultados desse inquérito, visando promover uma reforma generalizada e tão profunda quanto possível do ensino da Matemática. (GUIMARÃES, 2007, p. 21).

E, assim, realiza-se, como previsto, o que fica conhecido como "Seminário de Royaumont". ${ }^{3}$ Este Seminário constitui-se em referência maior para as propostas de reformulação da matemática escolar, que vem a concretizarse na elaboração de "Um programa moderno de Matemática para o ensino secundário"4, fruto dos trabalhos de uma segunda reunião, que ocorre em 1960, em Dubrovnik.

\footnotetext{
O Seminário foi realizado em finais do ano de 1959, no Cercle Culturel de Royaumont, em Asnièressur-Oise, França. As atividades tiveram duração de duas semanas e contaram com a participação de cerca de cinquenta delegados de dezoito países. (GUIMARÃES, H. M. Por uma matemática nova nas escolas secundárias: perspectivas e orientações curriculares da matemática moderna. In: MATOS, J. M.; VALENTE, W. R. (Org.). A matemática moderna nas escolas do Brasile de Portugal: primeiros estudos. São Paulo: Da Vinci / Capes-Grices, 2007. p. 22).

4 Trata-se do título de obra publicada sob os auspícios da OECE, Un programme moderne de mathématiques pour l'enseignement sécondaire, em 1961, onde há propostas de programas para os vários ciclos do ensino secundário (GUIMARÃES, 2007, p. 22).
}

Rev. Diálogo Educ., Curitiba, v. 8, n. 25, p. 583-613, set./dez. 2008 
Osvaldo Sangiorgi e o movimento da matemática moderna no Brasil 591

A nova proposta de reorganização do ensino da Matemática, por meio do ideário do Seminário de Royaumont, e de sua operacionalização resultante de Dubrovnik, desemboca num programa "fortemente influenciado pelas idéias estruturalistas dominantes na época, em particular no que se refere à Matemática e à Psicologia" (GUIMARÃES, 2007, p. 22). Marcadamente, os estudos de Jean Piaget e a concepção bourbakista ${ }^{5}$ da Matemática, constituem base para a elaboração das propostas.

O novo programa, assim, propõe "a valorização da Álgebra e da Geometria vetorial, com a correspondente desvalorização da Geometria de Euclides, na orientação axiomática dada ao estudo da Matemática, e numa valorização da linguagem e simbologia matemáticas" (GUIMARÃES, 2007, p. 32).

\section{O livro $L$ 'enseignement des mathématiques e os primeiros congressos do ensino de matemática no Brasil}

A historiografia brasileira identifica o II Congresso Nacional de Ensino da Matemática como lugar das primeiras discussões sobre o Movimento da Matemática Moderna (BÚRIGO, 1989, p. 72). O encontro ocorre na cidade de Porto Alegre, Rio Grande do Sul, no período de 29 de junho a 4 de julho de 1957.

A análise dos textos contidos nos Anais desse evento revela que três das comunicações apresentadas sugerem mudanças e modernização da matemática escolar no Brasil. A primeira delas, do Major Professor Jorge Emanuel Ferreira Barbosa, intitula-se Reflexos do desenvolvimento atual da matemática no ensino secundário. Ao início de seu texto, Barbosa adverte: "A principal finalidade desta tese é cuidar do problema da introdução no Curso Secundário da feição da Matemática Moderna." (CONGRESSO NACIONAL DE ENSINO DA MATEMÁTICA, 1959a, p. 272).

Depois de discorrer sobre aspectos da história da Matemática e das finalidades do Curso Secundário, Barbosa centra-se no imperativo do "ensino atualizado":

Vimos atrás que uma das finalidades do Curso Secundário se relaciona com a necessidade da educação de cientistas e, daí, com a formação de matemáticos. Assim, é necessário que a Matemática seja ensinada, no Curso Secundário, como ela é

\footnotetext{
Por 'concepção bourbakista' da Matemática deve-se entender aquela originada dos trabalhos do Grupo Bourbaki, nome de um grupo de matemáticos, formado em meados dos anos 30, na França. No entender desse Grupo, deve-se conceber a Matemática a partir de sua unidade, do método axiomático e do conceito de estrutura.
}

Rev. Diálogo Educ., Curitiba, v. 8, n. 25, p. 583-613, set./dez. 2008 
na época respectiva; o jovem deve ter idéia do estado em que realmente se encontra a Matemática da sua geração [...] Nesse sentido, a necessidade de introduzir-se na Escola Secundária a forma da Matemática Moderna se faz evidente. O conhecido matemático André Lichnerowicz reclama que o ensino secundário deve também iniciar os alunos “à ce qu'est l'esprit de la science contemporaine.” (CONGRESSO NACIONAL DE ENSINO DA MATEMÁTICA, 1959a, p. 278).

Apesar de essas considerações evidenciarem o contato do autor com a obra L'enseignement des mathématiques, Barbosa parece não ter se apropriado das discussões relativas ao paralelo entre estruturas algébricas e da inteligência. $\mathrm{Na}$ continuidade de seu texto, envereda pela discussão da "transferência de aprendizagem", sem trazer a análise piagetiana para o centro de sua exposição.

Por último, o trabalho de Barbosa tem como resultado as seguintes conclusões aprovadas em plenário:

A principal finalidade desta tese é cuidar do problema da introdução no Curso Secundário da feição da Matemática Moderna. Assim, propõe que entre as deliberações do II Congresso Nacional de Ensino da Matemática seja incluída a designação de um grupo de professores de diversas partes do país para fazerem a experimentação que julgarem necessária e, apresentarem, no próximo Congresso, relatório do seu trabalho a fim de que possamos, então sugerir, com autoridade, que conceitos novos convem ser admitidos, ou até onde se deve levar o aluno ao contato do que é a matemática de hoje em dia. (CONGRESSO NACIONAL DE ENSINO DA MATEMÁTICA, 1959a, p. 285).

Um segundo trabalho apresentado no Congresso de Porto Alegre é o do Professor Ubiratan D'Ambrosio, intitulado Considerações sobre o ensino atual da Matemática. D'Ambrosio, logo ao princípio, destaca a inadequação dos programas de Matemática brasileiros. Em seguida, dá o seu diagnóstico para essa afirmação:

Talvez a causa primeira deste estado de coisas esteja no fato de serem os programas ditados exclusivamente pela experiência. Uma estruturação do ensino da Matemática deve ser precedida de estudos cuidadosos, tendo presente o estado atual da ciência, no tocante ao seu desenvolvimento e às aplicações. (CONGRESSO NACIONAL DE ENSINO DA MATEMÁTICA, 1959a, p. 373).

Rev. Diálogo Educ., Curitiba, v. 8, n. 25, p. 583-613, set./dez. 2008 
Osvaldo Sangiorgi e o movimento da matemática moderna no Brasil 593

O texto de D'Ambrosio apesar de criticar o trato por demais empírico dos programas de matemática, discorre sobre experiências que o autor vinha desenvolvendo em suas aulas. No entanto, o autor dialoga com o livro L 'enseignement des mathématiques ${ }^{6}$ e faz aprovar as seguintes recomendações em plenário:

- que os programas levam em conta os valores formativo e informativo de cada assunto, com predominância do primeiro;

- que os programas permitam a aquisição gradual da abstração;

- que no estudo das propriedades dos números e dos polinômios sejam evidenciadas as propriedades que mais tarde facilitarão a compreensão das estruturas gerais da álgebra, como sejam as de grupo, anel e corpo. (CONGRESSO NACIONAL DE ENSINO DA MATEMÁTICA, 1959a, p. 378).

Por fim, um terceiro estudo levado ao Encontro é o trabalho do professor Osvaldo Sangiorgi. O texto tem por título: Matemática Clássica on Matemática Moderna, na elaboração dos programas do ensino secundário?. Sangiorgi inicia o trabalho considerando:

É esta a pergunta que tem dominado, atualmente, os estudiosos da Matemática do ensino secundário. Quernos parecer que, sendo a finalidade geral da instrução

6 Essa leitura e apropriação da obra de 1955 são confirmadas pelo autor em entrevistas concedidas tempos mais tarde a BÚRIGO, E. Z. Movimento da Matemática Moderna no Brasil: estudo da ação e do pensamento de educadores matemáticos nos anos 60. 1989. 285 f. Dissertação (Mestrado em Educação). Universidade Federal do Rio Grande do Sul, Porto Alegre - RS, 1989.; BORGES, R. A. S. A matemática moderna no Brasil: as primeiras experiências e propostas de seu ensino. 2005. 196 f. Dissertação (Mestrado em Educação Matemática). Programa de Estudos Pós-Graduados em Educação Matemática da PUC-SP, São Paulo, 2005. Para a pesquisadora Elisabete Búrigo, D'Ambrosio afirma ter dado notícia no Congresso "da existência de um movimento que estava surgindo nos Estados Unidos e Europa e do qual ele tomara conhecimento pela primeira vez através da publicação do livro" (BÚRIGO, 1989, p. 102). A Rosimeire Borges, o professor D'Ambrosio avalia o texto apresentado no Congresso como sendo resultado "de sua experiência como docente e ainda da influência obtida após a leitura de alguns trabalhos que ambicionavam os mesmos objetivos que ele. Dentre esses estava o livro publicado pela Commission Internationale pour l'étude et l'amélioration de l'enseignement des mathématiques, em 1955". Borges ainda destaca que D'Ambrosio refere-se à obra nos seguintes termos: "este trabalho, em que se procura principalmente mostrar de que modo a Matemática Moderna deve entrar no ensino médio, levando em conta considerações de ordem psicológicas, lógicas e matemáticas, foi decisivo em nossos estudos". (BORGES, 2005, p. 107-108).

Rev. Diálogo Educ., Curitiba, v. 8, n. 25, p. 583-613, set./dez. 2008 
função diretriz de cada época, não se pode dizer na verdade a última palavra quanto à investigação dos melhores princípios que devem nortear o ensino da Matemática. Não é outra, aliás, a afirmação dos ilustres membros da Commission Internationale pour l'étude et l'amélioration de l'enseignement des mathématiques feita, no livro L'enseignement des mathématiques editado na Suíça, em dezembro de 1956 (sic). Fazem parte dessa Comissão professores que, em campos diversos - psicológico, metodológico e prático - procuram dar uma contribuição ao aprimoramento do ensino da Matemática. (CONGRESSO NACIONAL DE ENSINO DA MATEMÁTICA, 1959a, p. 398).

A demonstração de estar em dia com a discussão internacional sobre o ensino de matemática constituiu apenas em um preâmbulo de sua palestra no II Congresso Nacional de Ensino da Matemática. Ele serviu como introdução às sugestões para o programa de matemática, trazido por Sangiorgi. O preâmbulo mostrou, ainda, que a aproximação de Sangiorgi com as discussões internacionais se deu pela leitura da obra L'enseignement des mathématiques, publicada em 1955.

Sem qualquer analise maior do livro, Sangiorgi considera, naquela altura que, à vista da interrogação "Matemática Clássica ou Matemática Moderna, na elaboração dos programas do ensino secundário?" cabe dizer simplesmente que:

[...] a principal diferença entre a matemática clássica e a matemática moderna reside no fato de a primeira ter por base os elementos simples (grifo do autor) tais como os números inteiros, o ponto, a reta etc., e a segunda um sistema operatório (grifo do autor), isto é, uma série de estruturas (Bourbaki), sobre as quais se assenta o edifício matemático, destacando-se entre elas as estruturas algébricas, as estruturas de ordem e as estruturas topológicas. (CONGRESSO NACIONAL DE ENSINO DA MATEMÁTICA, 1959a, p. 398-399).

Sendo assim, a resposta que dá para a mudança dos programas de matemática relativamente à matemática moderna é:

Cremos que as teorias cada vez mais complexas, a que é conduzida a investigação moderna, revelam-se pouco susceptíveis de virem ser já incorporadas no ensino secundário. É evidente, e os fatos nos tem provado, que a tendência é caminhar no sentido de satisfazer o anseio

Rev. Diálogo Educ., Curitiba, v. 8, n. 25, p. 583-613, set./dez. 2008 
Osvaldo Sangiorgi e o movimento da matemática moderna no Brasil 595

das novas gerações que estão vivendo num mundo ultramoderno, onde as ciências físico-matemáticas recebem continuamente novos e substanciosos impulsos. Mas - e este é o nosso pensamento - essa modelação aos tempos novos deve ser gradativa, a fim de serem evitados os malefícios decorrentes de transformações radicais [...]. (CONGRESSO NACIONAL DE ENSINO DA MATEMÁTICA, 1959a, p. 399).

Os Anais revelam que em boa medida as discussões sobre a modernização do ensino de matemática são motivadas pela apropriação que alguns participantes fizeram da obra L'enseignement des mathématiques. No entanto, não há aprofundamento dos debates e tudo indica que, na época, o texto apenas constitui um modo, uma referência para autorizar a discussão sobre mudanças. Quais são elas? Como elaborar um programa moderno para o ensino da Matemática? Tais questões não são levadas adiante. O II Congresso acaba por constituir-se num local de troca de experiências didáticas e propostas de programas de ensino baseadas no fazer cotidiano dos mestres em suas escolas. Por fim, o Congresso ratifica o Programa de Matemática aprovado no I Congresso Nacional do Ensino da Matemática, em 1955, para o ensino secundário, ${ }^{7}$ qual seja:

\section{Curso Ginasial}

$1^{a}$. Série: Aritmética; $2^{a}$. Série: Conclusão do programa de Aritmética e início da Álgebra; $3^{a}$. Série: Continuação do estudo da Álgebra e início da Geometria; 4a. Série: Álgebra e Geometria.

\section{Curso Colegial}

$1^{a}$. Série: Álgebra e Trigonometria; 2a. Série: Álgebra e Geometria no Espaço; $3^{a}$. Série: Álgebra e Análise Matemática (início) e Geometria Analítica (início).

Vindo o III Congresso Brasileiro do Ensino de Matemática, realizado no Rio de Janeiro, entre 20 e 25 de julho de 1959, pouco ou quase nenhum avanço é obtido nas discussões entre os professores de matemática participantes do evento, relativamente à modernização dos programas. Retornam, como nos congressos anteriores, a ganhar destaque as experiências pedagógicas, as sugestões de programas que contem pequeníssimas variações relativamente aos já estabilizados desde 1955, e

Essa conclusão está desde logo anunciada na "Sessão solene de instalação do 3. ${ }^{\circ}$ Congresso Brasileiro do Ensino da Matemática", realizada no auditório do Ministério da Educação e Cultura, às 21 horas do dia 20 de julho de 1959, transcrita nos Anais desse congresso.

Rev. Diálogo Educ., Curitiba, v. 8, n. 25, p. 583-613, set./dez. 2008 
as experiências metodológicas de ensino dos conteúdos já tradicionais. Uma explicação para isso deve levar em conta que uma parte significativa das lideranças entre os professores - que dirige as diferentes sessões dos dois primeiros encontros - é formada de autores de livros didáticos de matemática. Ao que parece, esses congressistas participam das discussões, também, para preservar uma organização dos conteúdos seriados de matemática que esteja de acordo com seus manuais de ensino e suas experiências pedagógicas. Nesse caso, também representam interesses editoriais. Cabe, no entanto, citar uma recomendação aprovada pelo III Congresso, de:

Solicitar aos Srs. Professores realizem experiências no Curso Secundário sobre a introdução de noções de Matemática Moderna e levem ao $4 .^{\circ}$ Congresso Brasileiro do Ensino da Matemática o resultado das mesmas. (CONGRESSO NACIONAL DE ENSINO DA MATEMÁTICA, 1959b, p. 214).

Posteriormente, em 1960, ano seguinte à realização do III Congresso, alguns fatores contribuíram para que fosse acelerado o processo de mudança, com vistas a uma matemática moderna no ensino secundário brasileiro. Toma a dianteira das propostas de modernização, o professor Osvaldo Sangiorgi.

\section{Osvaldo Sangiorgi e o processo de oficialização de um programa de matemática moderna brasileiro}

Como se mostra anteriormente, a posição do professor Osvaldo Sangiorgi diante das discussões sobre a introdução da Matemática Moderna no ensino secundário brasileiro é de cautela. Não está interessado em transformações radicais dos programas de ensino de matemática. ${ }^{8}$

Essa opinião, no entanto, muda muito com o estágio que Sangiorgi realiza, em 1960, nos EUA. Sangiorgi, por meio dele, consolida sua posição nacional, obtém certa projeção no estrangeiro e reformula totalmente sua coleção de livros didáticos para o ginásio. O estágio convence-o de que as mudanças nos

8 Talvez esse posicionamento de cautela, naquela altura, possa ser compreendido, dentre outros fatores, como uma defesa oculta da organização de seus livros didáticos, sobretudo aqueles pertencentes à coleção Matemática - curso ginasial - 4 volumes, que são verdadeiros best-sellers didáticos dos anos 50, publicados pela Companhia Editora Nacional. Mudar a programação de matemática implicaria numa reformulação das obras e a arriscar-se num mercado editorial que dava sinais de enorme crescimento, sobretudo em termos de autores de livros didáticos de matemática.

Rev. Diálogo Educ., Curitiba, v. 8, n. 25, p. 583-613, set./dez. 2008 
Osvaldo Sangiorgi e o movimento da matemática moderna no Brasil 597

livros didáticos são inevitáveis e imperiosas, sob pena de ser ultrapassado por outros autores. Além disso, coloca-o em contato com propostas modernizadoras já em andamento em escolas dos Estados Unidos.

É possível acompanhar esse momento pelo próprio relato de Sangiorgi, publicado na revista Atualidades Pedagógicas, em seu número de set-dez de 1960. Nele, Sangiorgi descreve a sua experiência, num texto intitulado Curso de Verão, com subtítulo esplêndida oportunidade para a renovação dos conhecimentos dos professores e atualização de programas e métodos de ensino. Com bolsa da Pan American Union e National Science Foundation, Sangiorgi realiza um estágio na Universidade de Kansas, EUA, de junho a agosto de 1960.

No texto, Sangiorgi cunha, para a ambiência escolar brasileira, uma das representações que serão propagadas nos estudos posteriores sobre o que ficou conhecido como Movimento da Matemática Moderna: o interesse estadunidense na modificação dos programas e métodos do ensino de matemática e ciências como fruto da Guerra Fria:

A verdade é que depois do lançamento do 'Sputinik', pelos russos, em 1957, houve como que uma nova tomada de posição, por parte dos educadores norte-americanos, em relação à estrutura do ensino de seu país, notadamente na parte que dizia respeito à Matemática e às Ciências, de um modo geral. (SANGIORGI, 1960, p. 8-9).

Sangiorgi, no texto da Revista Atualidades Pedagógicas, tece grandes elogios à iniciativa norte-americana de promoção dos cursos de verão, e às condições materiais de organização e de conteúdo desses eventos. Um dos destaques que ele faz ao curso relaciona-se às classes experimentais e ao modo de elaboração de novos livros didáticos:

Muitas observações construtivas foram feitas em classesambientes (cerca de 25 alunos) onde a matéria explanada por um dos bolsistas era discutida após a aula. Os livros didáticos (também experimentais) foram elaborados por Grupos de Estudos (School Mathematics Study Group; Mathematical Association of América; Comissiono on Mathematics of the College Entrance Examination Board; Committee on School Mathematics - Illinois) que assim passaram a ter o seu primeiro contato com os alunos. (SANGIORGI, 1960, p. 11).

De volta ao Brasil, Sangiorgi logo começa a promover articulações entre professores da Universidade de São Paulo, professores efetivos de matemática da rede oficial de ensino, a mídia e a Secretaria de Educação do estado de São

Rev. Diálogo Educ., Curitiba, v. 8, n. 25, p. 583-613, set./dez. 2008 
Paulo, com vistas à modificação dos programas de matemática, à semelhança do que vê nos Estados Unidos. O jornal "Folha de São Paulo", no dia 11 de outubro de 1960, noticia: "Professores de São Paulo visam à reforma dos programas e métodos do ensino de matemática." No texto, a informação de que a Secretaria da Educação, em seu plano de reestruturação geral, cria um grupo de trabalho para estudo do ensino de matemática, coordenado pelo professor Osvaldo Sangiorgi (NAKASHIMA, 2007).

Posteriormente a essa reportagem, um verdadeiro bombardeio de notícias sobre as alterações previstas para a matemática, passa a ser tema na mídia impressa. Os jornais de São Paulo, sobretudo, acompanham cada passo e iniciativa de Osvaldo Sangiorgi, em torno das mudanças no ensino de matemática, rumo à matemática moderna. Eles noticiam cursos para professores, com dispensa de ponto, pela Secretaria da Educação; vinda de pesquisadores estrangeiros para palestras; criação do GEEM - Grupo de Estudos do Ensino de Matemática, sob a coordenação de Osvaldo Sangiorgi; ${ }^{9}$ Congressos do Ensino de Matemática e a Matemática Moderna; entrevistas e depoimentos de Sangiorgi, dentre outras notícias sobre o ensino moderno de matemática. Mas, faltava um programa, uma referência oficial para a mudança nos livros didáticos.

Logo após a criação do GEEM, as atividades com professores, com a divulgação da matemática moderna são intensas. Mais frequentes são, ainda, as reuniões do Grupo para o estabelecimento do que passam a denominar "assuntos mínimos para um programa de matemática moderna para o ginásio", como atesta

\footnotetext{
9 Depois de sua volta ao Brasil, Sangiorgi consegue organizar um curso de aperfeiçoamento para professores de matemática, através de acordo com a National Science Foundation, que garantiu a vinda do professor George Springer. O curso é realizado no Instituto Mackenzie, durante oito semanas, de agosto a setembro de 1961. Em convênio com Secretaria de Educação, Sangiorgi obtém a liberação de ponto para a participação de professores da rede pública, num total de 25. Essa atividade abre caminho para a criação, aos moldes do School Mathematics Study Group, dos EUA, do GEEM - Grupo de Estudos do Ensino da Matemática, em outubro de 1961. Vários alunos desse curso tornam-se os primeiros professores a realizarem experiências com a matemática moderna no ensino secundário. (BÚRIGO, 1989, p. 105). Um desses alunos, a professora Renate Gompertz Watanabe, guarda em seu acervo pessoal, o diploma recebido no curso. Nele consta "Curso de Especialização em Matemática", com aprovação nas provas e trabalhos exigidos no curso, nas disciplinas de "Lógica Matemática e Aplicações", "Teoria dos Conjuntos", “Álgebra Moderna” e "Seminários de Ensino de Matemática", todas com grau 'A', com distinção. Assinam o documento o reitor da Universidade Mackenzie, Henrique Thut; o diretor da Faculdade de Filosofia, Willie Maurer; o professor George Springer, da Universidade de Kansas-EUA; o professor Osvaldo Sangiorgi, da Universidade Mackenzie; o professor Luiz Jacy Monteiro, da Universidade de São Paulo e o professor Alésio De Caroli, da Universidade de São Paulo.
}

Rev. Diálogo Educ., Curitiba, v. 8, n. 25, p. 583-613, set./dez. 2008 
Osvaldo Sangiorgi e o movimento da matemática moderna no Brasil 599

a base de dados de recortes de jornais organizada por Nakashima (2007). Nessas reuniões são debatidas experiências de professores do Grupo com a matemática moderna no ensino secundário. ${ }^{10}$

Esses encontros acabam fornecendo subsídios para a elaboração dos "assuntos mínimos", provavelmente organizados por Sangiorgi. As notícias dos encontros e reuniões do GEEM indicam, ainda, que eles servem para que o Grupo se prepare para levar uma proposta de São Paulo, de um programa de matemática moderna para o ginásio, no IV Congresso Brasileiro do Ensino da Matemática, a ser realizado em Belém do Pará, entre os dias 22 e 28 de julho de 1962.

Aproveitando os dispositivos da nova Lei de Diretrizes e Bases da Educação Nacional, aprovada em 1961, de descentralização e criação dos Sistemas Estaduais, abre-se caminho para os debates sobre o currículo escolar, em nível dos estados brasileiros. Em termos do ensino de matemática o lugar privilegiado de discussão de novas propostas trazidas pelos estados passa a ser o IV Congresso. Sangiorgi tem, tudo indica, absoluta clareza dessa nova possibilidade dada por lei maior, que reveste de grande importância o Evento de Belém do Pará. ${ }^{11}$

Antes mesmo da realização do IV Congresso, o GEEM, dá divulgação à sua proposta, submetida e aprovada pelo $\mathrm{V}$ Encontro de Mestres, realizado na capital paulista, de 27 a 28 de junho de 1962, sob o patrocínio da Cades, órgão federal encarregado de cursos de formação de professores secundários. Através de Sangiorgi, o novo programa é ainda levado à apresentação na reunião de professores

10 Para que se tenha idéia dessas experiências trazidas às reuniões do GEEM há, por exemplo, em maio de 1962, um encontro onde ganham destaque a apresentação da professora Elza Babá, do Ginásio Estadual de Vila Mazzei, que mostra os resultados da introdução dos conceitos de número e numeral na primeira série ginasial. A reunião também apreciou o trabalho do professor Ruy Madsen Barbosa, professor da Faculdade de Filosofia de Araraquara, que tratou do estudo de matrizes no ciclo colegial. (Base de dados de NAKASHIMA, M. O papel da imprensa no Movimento da Matemática Moderna. 2007. 205 f. Dissertação (Mestrado em Educação Matemática). Programa de Estudos Pós-Graduados em Educação Matemática da PUC-SP, São Paulo, 2007).

11 Apenas como exemplo dessa dinâmica de ação do GEEM., registrada na base de dados de jornais de época, construída por Nakashima (2007), a reunião realizada no dia 26 de maio de 1962, que é noticia do jornal "O Estado de São Paulo" do dia anterior, informa: "Reunião para estudo do ensino da Matemática": "Reunir-se-á amanhã, às 14 e 30, na Faculdade de Filosofia Mackenzie, o Grupo de Estudos do Ensino da Matemática. Os trabalhos obedecerão à seguinte ordem: a) comunicações sobre experiências que vem sendo realizadas, sobre a introdução da Matemática Moderna no Curso Secundário; b) discussão dos assuntos mínimos de um programa de Matemática para o Ginásio, em face à Lei de Diretrizes e Bases; c) atividades relacionadas com o IV Congresso Nacional de Ensino da Matemática, em julho vindouro, em Belém do Pará. Os professores dos estabelecimentos secundários oficiais, efetivos em Matemática, que comparecerem a essa reunião, serão dispensados do ponto nesse dia, segundo portaria do Departamento de Educação, publicada no Diário Oficial de 11/05/62".

Rev. Diálogo Educ., Curitiba, v. 8, n. 25, p. 583-613, set./dez. 2008 
da Seção K-Educação, dentro do temário Introdução da Matemática Moderna no Curso Secundário, na XIV Reunião Anual da Sociedade Brasileira para o Progresso da Ciência. O novo programa tem divulgação impressa por meio do boletim "Notícias do IBECC" de julho de $1962^{12}$ (NAKASHIMA, 2007).

$\mathrm{Na}$ apresentação do programa moderno a advertência:

Quando se fala na introdução da Matemática Moderna no ensino secundário, não se deve pensar que se pretende ensinar um programa completamente diferente dos programas já conhecidos. O que se deseja essencialmente com Modernos Programas de Matemática (e esta seria a expressão aconselhada) é estudar os mesmos assuntos da Matemática, conhecidos como essenciais na formação do jovem ginasiano, usando, porém, uma linguagem moderna (grifo do texto) que seja mais atraente às novas gerações. Essa linguagem moderna envolve substancialmente o conceito de conjunto (grifo do texto), e deve atender à formação das estruturas matemáticas (grifo do texto), que permitam, com menos esforço, melhor aproveitamento das estruturas mentais já existentes no aluno, e dão ênfase ao caráter da Matemática atual. (IBECC, 1962).

Desse modo, o GEEM presidido por Sangiorgi, leva ao IV Congresso, os "assuntos mínimos para um moderno programa de matemática". $\mathrm{Na}$ avaliação que faz sobre a proposta presente no Congresso, da professora Lucília Bechara Sanchez, uma das integrantes do Grupo, anos mais tarde, em depoimento à pesquisadora Elisabete Búrigo, fica clara a força do Grupo paulista na definição pioneira de um programa de matemática moderna para o Brasil:

Esse grupo que fez o grupo do Springer, quando fomos a Belém, nós fomos em bloco, foi a primeiras vez que um Congresso teve um trabalho organizado, o GEEM, com um trabalho de grupo já. [...] Tinha a Renate Watanabe,

12 O IBECC - Instituto Brasileiro de Educação, Ciência e Cultura constitui-se como sessão da Unesco, em São Paulo. Suas atividades passam a ter grande destaque na década de 60, com a realização de encontros sobre a melhoria do ensino de ciências no curso secundário. Em julho de 60, por exemplo, o Instituto realiza, com o concurso da Fundação Ford, conferência sobre o ensino de ciências. Nela participam professores estadunidenses vindos ao Brasil por intermédio da National Science Foundation. (NAKASHIMA, 2007).

Rev. Diálogo Educ., Curitiba, v. 8, n. 25, p. 583-613, set./dez. 2008 
Osvaldo Sangiorgi e o movimento da matemática moderna no Brasil 601

aí ele (Sangiorgi) trouxe o Douglas, um monte de gente, o Castrucci, todos produziam trabalho. Eu fazia trabalho de sala de aula, a Manhúcia, a Elza Babá. Isso pesa num congresso. Então, em Belém do Pará, o GEEM fez sucesso, tanto assim que nós trouxemos o Congresso para São Paulo no ano seguinte. (BECHARA - depoimento oral apud BÚRIGO, 1989, p. 107).

O sucesso e aprovação do trabalho do GEEM, liderado por Osvaldo Sangiorgi, na apresentação da nova proposta de modernização do ensino de matemática faz com que, na primeira publicação do Grupo, em finais de 1962, patrocinada pelo IBECC e pela Editora Universitária da Universidade de São Paulo, tenha na Introdução aos "assuntos mínimos” os seguintes dizeres:

O GEEM de São Paulo, apresentando ao IV Congresso Brasileiro do Ensino de Matemática, a contribuição de sua equipe acerca do atual problema da modernização do ensino da Matemática no curso médio, almejou, ir ao encontro do que é possibilitado pela Lei de Diretrizes e Bases da Educação Nacional, na certeza de que dessa Assembléia máxima - dos professores de matemática do Brasil, reunida em Belém do Pará, surgirão reais diretrizes para um verdadeiro norte do ensino da Matemática nas escolas secundárias do país. (GEEM, 1962, p. 83).

\section{Um programa pioneiro para ensino de matemática moderna no Brasil}

O programa elaborado pelo GEEM, sob a coordenação de Osvaldo Sangiorgi, elenca vinte e quatro itens de conteúdos de ensino para as quatro primeiras séries do ensino secundário (ginásio) e dezoito para as três séries finais (colegial). Ao lado de cada item de conteúdo, de modo sumário, estão postas as sugestões didático-metodológicas para abordagem dos temas. Assim, por exemplo, para o ginásio:

Rev. Diálogo Educ., Curitiba, v. 8, n. 25, p. 583-613, set./dez. 2008 


\begin{tabular}{|c|c|}
\hline ASSUNTOS MÍNIMOS & SUGESTÕES \\
\hline $\begin{array}{l}\text { 1- Números inteiros; operações fundamentais; } \\
\text { propriedades. Sistemas de numeração. }\end{array}$ & $\begin{array}{l}\text { 1- A idéia de conjunto deveria ser a dominante; as } \\
\text { propriedades das operações com os números } \\
\text { inteiros devem ser ressaltadas como início das } \\
\text { estruturas matemáticas. Lembrar a importância de } \\
\text { outros sistemas de numeração, além do decimal. }\end{array}$ \\
\hline $\begin{array}{l}\text { 2- Divisibilidade; múltiplos e divisores; números } \\
\text { primos. }\end{array}$ & $\begin{array}{l}\text { 2- O uso da linguagem de conjuntos e operações } \\
\text { entre conjuntos, poderá trazer novos centros de } \\
\text { interesse na explanação da matéria. }\end{array}$ \\
\hline$(\ldots)$ & $(\ldots)$ \\
\hline $\begin{array}{l}\text { 12- Função; representação gráfica cartesiana de uma } \\
\text { função. }\end{array}$ & $\begin{array}{l}\text { 12- Dar a noção fundamental de função como } \\
\text { correspondência; introduzir sistema de coordenadas } \\
\text { no plano; estudar a função linear: } \mathrm{y}=\mathrm{ax}+\mathrm{b}\end{array}$ \\
\hline$(\ldots)$ & $(\ldots)$ \\
\hline $\begin{array}{l}\text { 19- Número irracional e número real; operações } \\
\text { fundamentais; cálculo de radicais. }\end{array}$ & $\begin{array}{l}\text { 19- Ressaltar a permanência das propriedades já } \\
\text { introduzidas com os números racionais; resolver } \\
\text { equações e sistemas do } 1^{\circ} \text {. Grau com coeficientes } \\
\text { reais. Representação gráfica do número real na reta. }\end{array}$ \\
\hline$(\ldots)$ & $(\ldots)$ \\
\hline $\begin{array}{l}\text { 24- Áreas dos polígonos; medida da circunferência e } \\
\text { área do círculo. }\end{array}$ & 24- Noção do número? \\
\hline
\end{tabular}

E para o colégio:

\begin{tabular}{|c|c|}
\hline ASSUNTOS MÍNIMOS & SUGESTÕES \\
\hline $\begin{array}{l}\text { 1- Função de } 2^{\circ} \text {. Grau. Estudo completo do } \\
\text { trinômio do } 2^{\circ} \text {. Grau e aplicações. }\end{array}$ & $\begin{array}{l}\text { 1- No estudo do trinômio, ressaltar o aspecto gráfico } \\
\text { e nas aplicações, as inequações do } 2^{\circ} \text {. Grau. }\end{array}$ \\
\hline$(\ldots)$ & $(\ldots)$ \\
\hline $\begin{array}{l}\text { 8- Transformações pontuais: translação, rotação, } \\
\text { simetria e homotetia. }\end{array}$ & $\begin{array}{l}\text { 8- Ressaltar as estruturas definidas através desses } \\
\text { tipos de transformação. }\end{array}$ \\
\hline$(\ldots)$ & $(\ldots)$ \\
\hline $\begin{array}{l}\text { 14- Sistema de equações lineares. Noção de matrizes: } \\
\text { aplicações. }\end{array}$ & $\begin{array}{l}\text { 14- O estudo pode ser feito através da teoria dos } \\
\text { determinantes ou preferivelmente, pelas matrizes. } \\
\text { Ressaltar as estruturas algébricas das operações com } \\
\text { matrizes (anel e espaço vetorial). }\end{array}$ \\
\hline$(\ldots)$ & $(\ldots)$ \\
\hline $\begin{array}{l}\text { 18- Noção de limite, continuidade e derivadas. } \\
\text { Elementos de cálculo integral; aplicações ao cálculo } \\
\text { de áreas e volumes. }\end{array}$ & $\begin{array}{l}\text { 18- Dar noções intuitivas, que permitam deduzir as } \\
\text { principais propriedades, que serão utilizadas nas } \\
\text { aplicações a outras ciências. }\end{array}$ \\
\hline
\end{tabular}

Rev. Diálogo Educ., Curitiba, v. 8, n. 25, p. 583-613, set./dez. 2008 
Osvaldo Sangiorgi e o movimento da matemática moderna no Brasil 603

A análise da proposta permite dizer que o anunciado para o novo programa, por meio de seus "assuntos mínimos" é cumprido. Assim, o moderno programa expressa a concepção de que não se trata de uma nova matemática, mas a antiga com uma linguagem moderna. Para além do entendimento próprio que dá o GEEM, representado por Osvaldo Sangiorgi, às discussões internacionais, há que se notar uma estratégia que busca não romper com a organização e ordenação já estabelecida para a matemática escolar. Grosso modo, ela está presente - em termos da descrição de itens de conteúdo para o ginásio - na coleção campeã de vendas de Sangiorgi, Matemática - curso ginasial - $1^{a}$. Série. ${ }^{13}$

\section{A matemática moderna nas escolas do Brasil: os livros didáticos de Sangiorgi}

Desde o primeiro estudo realizado sobre o Movimento da Matemática Moderna no Brasil ${ }^{14}$ fica claro o papel dos livros didáticos como veículos privilegiados da divulgação da nova proposta. Cabe aos manuais escolares "falar" diretamente aos professores brasileiros, para além de debates e discussões ocorridas em Congressos e cursos. O livro didático de matemática moderna vai, por meio de sua circulação e uso no cotidiano escolar, permitir a apropriação por alunos e professores de uma nova matemática escolar. Aqui, novamente, está presente o pioneirismo de Osvaldo Sangiorgi. Seus novos livros didáticos de matemática moderna tem um estrondoso sucesso editorial. E vários são os fatores a explicar esse fenômeno, começando pelo contexto da educação no início da segunda metade do século XX, no principal estado brasileiro.

O crescimento inaudito do número de ginásios no estado e na capital de São Paulo, aliado a um grau maior de flexibilidade para os estados da federação organizarem seu próprio ensino secundário e o desenvolvimento acelerado do parque editorial paulista na produção de livros didáticos caracterizam a ambiência educacional nos anos finais da década de 50.

Por essa altura, Osvaldo Sangiorgi já é reconhecido como referência-maior para o ensino de matemática. Sangiorgi, como grande autor de livros didáticos, carrega consigo a autoridade matemática, didática e experiência

13 Um estudo mais detalhado da trajetória editorial está no texto "Osvaldo Sangiorgi - um bestseller" que compõe capítulo do livro VALENTE, W. R. (Org.). Osvaldo Sangiorgi: um professor moderno. São Paulo: Annablume/CNPq (no prelo).

14 A pesquisadora Beatriz D'Ambrosio em seu texto "The dynamics and consequences of the modern mathematics reform movement for Brazilian mathematics education", considerado o primeiro estudo do MMM no Brasil, destaca o papel que tiveram os livros didáticos de matemática na difusão do Movimento.

Rev. Diálogo Educ., Curitiba, v. 8, n. 25, p. 583-613, set./dez. 2008 
de grande articulador de ações conjuntas entre a editora de suas obras - a Cia. Editora Nacional - e a Secretaria da Educação, na promoção de encontros e cursos para professores.

Na pesquisa de Elisabete Búrigo, essa capacidade de Sangiorgi é atestada na entrevista dada pelo professor Ubiratan D’Ambrosio:

Ele ia muito para o interior, ele tinha muitos contatos no interior e dizia: 'as pessoas (os professores) querem mais, precisam mais'. [...] então tinha o interesse econômico (de propaganda dos livros), mas tinha muito o aspecto de cidadão, de líder que queria aglutinar forças. [...] era um homem empreendedor, ele quando levava uma coisa a cabo ia até o fim. (D'AMBROSIO apud BÚRIGO, 1989, p. 102).

Assim, Osvaldo Sangiorgi está presente em praticamente todos os espaços ligados ao ensino de matemática. Com trânsito fácil por entidades e órgãos oficiais da educação paulista, é responsável por organizar e sugerir programas de ensino; representa São Paulo nos eventos nacionais; é autor de livros didáticos que mais e mais se impõem às escolas secundárias através de dezenas de edições; integra bancas de concurso de professores e de alunos nos exames de admissão ao ginásio, definindo pontos e provas de matemática.

Todo o cenário construído para a entrada da matemática moderna no ensino brasileiro tem, no lançamento de uma coleção de livros didáticos, o seu ápice. É em meados de 1963, para uso no ano letivo de 1964, quando eles já estão nos ginásios. Nesse ano, a Cia. Editora Nacional lança no mercado de livros escolares mais de 240 mil exemplares do volume 1, da obra Matemática - curso moderno, de Osvaldo Sangiorgi. ${ }^{15}$

O lançamento da matemática moderna, por meio dos livros didáticos para o ginásio, tem na imprensa, mesmo que indiretamente, um apoio fantástico. No dia 12 de julho de 1963, o jornal "Folha de S. Paulo", apresenta como manchetes a Matemática Moderna. A primeira, intitulada O que é a Matemática Moderna na opinião do diretor do GEEM, apresentando uma longa entrevista com Sangiorgi, que não faz menção a seus livros, mas enuncia todas as vantagens e conveniências do ensino de matemática moderna, ancorada nos últimos avanços científicos; a segunda, Verdadeira revolução vai sofrer o ensino da Matemática, é desenvolvida com um texto que, logo à primeira frase menciona: "1964 vai ficar na história da

5 Dados coletados dos mapas de edições do arquivo histórico da Cia. Editora Nacional, hoje em poder do IBEP - Instituto Brasileiro de Edições Pedagógicas, em São Paulo.

Rev. Diálogo Educ., Curitiba, v. 8, n. 25, p. 583-613, set./dez. 2008 
Osvaldo Sangiorgi e o movimento da matemática moderna no Brasil 605

cultura brasileira como o Ano 1 da Matemática Moderna”. Efetivamente, 1964 é o ano 1, do volume 1, dos novos livros didáticos de matemática para o ginásio, livros de matemática moderna, de modo pioneiro, escritos por Osvaldo Sangiorgi.

Diferentemente do que presencia nos Estados Unidos, quando os novos livros são elaborados coletivamente, passando por classes experimentais, até ganharem versão final, Sangiorgi publica seu curso moderno, obra assinada por um só autor, que não teve trajetória experimental. Apesar disso, na contracapa, Sangiorgi faz a seguinte referência:

$\mathrm{O}$ autor agradece, sensibilizado, a todos aqueles que, direta ou indiretamente, colaboraram na feitura deste livro, em particular aos colegas do 'Grupo de Estudos do Ensino da Matemática' - GEEM - pelas magníficas sugestões e discussões de certos tópicos aqui presentes. (SANGIORGI, 1963).

A nova coleção de obras didáticas de matemática sedimenta oficiosamente uma nova programação para o ensino de matemática no Brasil. A estratégia utilizada é convencer os professores de que o programa mudou, que há uma nova matemática a ser ensinada e que a sua obra pioneira traz essa nova programação. Assim escreve Sangiorgi, nas páginas iniciais do primeiro volume de sua coleção de quatro tomos, a serem utilizados nos ginásios brasileiros, a propósito dos assuntos abordados no livro, que:

Estão explicados neste Volume 1, e fazem parte dos vinte e quatro itens que compõem os Assuntos Mínimos para um Moderno Programa de Matemática para os Ginásios, com as respectivas sugestões para seu desenvolvimento, apresentadas pelo Grupo de Estudos do Ensino da Matemática (GEEM), de São Paulo, em trabalho aprovado unanimemente pelo IV Congresso Brasileiro do Ensino da Matemática (Belém, Pará, julho de 1962), e readaptados no Curso de Treinamento Básico para Professores Secundários (Diretoria do Ensino Secundário do Ministério da Educação e Cultura), realizado em Brasília, de 25 a 30 de novembro de 1963. (SANGIORGI, 1963).

Os cuidados com a apresentação do novo, da nova matemática, envolvem detalhes de edição importantes. O volume 1, do curso moderno de Sangiorgi, contem um Prefácio, com um texto destinado aos alunos: "Uma palavra para você que inicia o ginásio...”. Em forma de uma carta aos ginasianos, Sangiorgi faz questão de caracterizar a nova matemática e que ela, agora, iria ser estudada com prazer:

Rev. Diálogo Educ., Curitiba, v. 8, n. 25, p. 583-613, set./dez. 2008 
Você vai iniciar agora o estudo da Matemática de um modo diferente daquele pelo qual seus irmãos e colegas mais velhos estudaram. Sabe por quê? Porque Matemática, para eles, na maioria das vezes, era um 'exagero de cálculos', 'problemas complicados, trabalhosos e fora da realidade' que a tornavam, quase sempre, um fantasma! Hoje, na Era Atômica em que vivemos isto é trabalho para as máquinas (os fabulosos computadores eletrônicos de que tanto falam os jornais...), razão pela qual você vai aproveitar o seu precioso tempo aprendendo o verdadeiro significado e as belas estruturas da Matemática Moderna. (SANGIORGI, 1963, p. 13).

Na continuidade de sua mensagem aos alunos, explicita sua convicção nas teorias modernas piagetianas da aprendizagem, que fazem paralelo com a nova organização da matemática a ser ensinada e que valem para qualquer disciplina:

Então, você perceberá, por exemplo, uma certa semelhança entre o modo de raciocinar em Matemática e nas outras matérias de seus estudos, como Português, História, Geografia, Ciências, Música, Educação Física etc. Conhecer Matemática dessa forma é o principal objetivo deste livro em que você vai começar a estudar e que se completará com o auxílio indispensável de seu professor. Vamos, pois, estudar Matemática com prazer! (SANGIORGI, 1963, p. 13).

O novo livro didático, para a nova matemática, é também novo em sua materialidade. Nova diagramação na apresentação dos conteúdos escolares, no uso de tipos de letras e números de diferentes tamanhos e formas; inclusão de cores nas páginas internas, fotografias, desenhos. Para trás fica a estética dos livros de matemática dos anos 50. A nova coleção, dentre outros elementos, adota, também, a cor como informação. ${ }^{16}$

\footnotetext{
16 De acordo com o pesquisador GUIMARÃES, L. As cores na mídia: a organização da corinformação no jornalismo. São Paulo: Annablume, 2003. p. 31), “considera-se a cor como informação todas as vezes em que sua aplicação desempenhar uma dessas funções responsáveis por organizar e hierarquizar informações ou lhes atribuir significado, seja sua atuação individual e autônoma ou integrada e dependente de outros elementos do texto visual em que foi aplicada (formas, figuras, texturas, textos, ou até mesmo sons e movimentos, como em produtos multimídia)."
}

Rev. Diálogo Educ., Curitiba, v. 8, n. 25, p. 583-613, set./dez. 2008 
Osvaldo Sangiorgi e o movimento da matemática moderna no Brasil 607

O lançamento da coleção de matemática moderna para o ginásio tem, ainda, um outro aspecto que, à época, pode ser considerado inovador. A nova coleção retoma um elemento que há muito havia deixado de fazer parte das obras didáticas para o ensino de matemática: o Livro do Mestre. Para tanto, acompanha cada volume da Matemática - curso moderno, um guia para professores. Assim, são publicados os Guia para uso dos professores, volumes 1, 2, 3 e 4. Neles, Sangiorgi expressa a didática da matemática moderna, buscando guiaros professores no trabalho pedagógico com os novos temas. Os Guias apresentavam: "1 Observações de ordem pedagógica; 2 - Referências bibliográficas; 3 - Respostas às questões propostas no livro".

O sucesso da obra é confirmado pelas novas edições do primeiro volume: em 1965, mais de 250 mil novos livros são editados e assim, anualmente, o livro tem tiragens na casa dos 250 mil exemplares, até 1967, alcançando a sua $10^{a}$ edição, como atesta o "Mapa de Edições" da Editora. ${ }^{17}$

A obra de Sangiorgi, autor que pela primeira vez elabora um texto didático de matemática moderna para ser utilizado nos ginásios, espalha-se pelo Brasil. Os arquivos da Cia. Editora Nacional contém cartas de diversos pontos do país, que pedem a biografia de seu autor. São cartas de professores de matemática, de normalistas e, também, de alunos. Isso indica que a coleção de Sangiorgi ganha novos mercados, substituindo autores já conhecidos pelo público escolar. As cartas pedem uma proximidade maior do autor das obras que estão sendo utilizadas no dia-a-dia escolar. ${ }^{18} \mathrm{~A}$ Editora, sempre atenta, responde aos pedidos enviando uma biografia sumária de Sangiorgi.

A coleção de Sangiorgi, também, ultrapassa fronteiras e segue para além-mar. Em dezembro de 1967, a Folha Informativa, periódico das escolas técnicas portuguesas, manifesta interesse em conhecer as transformações pelas quais a matemática escolar passa no Brasil. Assim, o redator do periódico informa que "os brasileiros tinham já o seu Programa de Matemática Moderna para os cursos ginasiais", descrevendo os vinte quatro itens desse programa. Na continuidade do artigo, no número seguinte da revista, em 1968, o autor menciona que mais importante que o programa que, segundo ele, não apresenta novidades, é o

17 No que toca às edições do Guias, destinados aos professores, de acordo com os arquivos da Cia. Editora Nacional, o primeiro volume é lançado em março de 1964, com tiragem de mais de cinco mil exemplares. Em 1965, já seriam 12 mil. Em média, até o início dos anos 70, anualmente foram publicados cinco mil exemplares de cada volume.

18 Um exemplo dessas cartas foi a enviada por alunos da cidade de Andradas, MG, datada de $1^{\circ}$. de abril de 1967. O texto, endereçado à Cia. Editora Nacional, bastante singelo, dizia: "Somos alunos da $2^{\text {a }}$. série ginasial do Ginásio Estadual de Andradas. O autor de nosso livro de matemática é o estimado Osvaldo Sangiorgi. Nada sabemos sobre ele, gostaríamos, portanto, de que nos enviassem seus dados biográficos para que o conheçamos melhor."

Rev. Diálogo Educ., Curitiba, v. 8, n. 25, p. 583-613, set./dez. 2008 
tratamento dos temas. Assim, seleciona alguns deles e descreve - apesar de não citar nominalmente Sangiorgi- como o Guia para uso dos Professores trata os assuntos didática e pedagogicamente.

$\mathrm{Na}$ América do Sul, os textos de Sangiorgi também tem repercussão. Nos arquivos da Editora estão pedidos, da coleção de matemática moderna para o ginásio, de países como Uruguai e Argentina.

Em 1968, é realizada uma primeira revisão do livro Matemática - curso moderno, volume 1, para os ginásios. A nova edição é cercada de muita divulgação pela Editora. A Cia. Editora Nacional edita um folheto especial para isso. Na capa principal do material, os dizeres: "Nova edição! Ampliada e Renovada". No conteúdo do material, textos assinados pela Editora e por Sangiorgi. A Editora destaca que Sangiorgi está retornando do extremo oriente onde, a convite a Sociedade de Educação Matemática Japonesa, realiza diversas conferências sobre o que vem sendo realizado por meio da OEA - Organização dos Estados Americanos, relativamente ao ensino de matemática. No folder, ainda, está estampada uma foto que mostra Sangiorgi, junto aos japoneses, numa palestra que ocorre em outubro de 1967. Na legenda da foto, os dizeres de que a palestra fotografada mostra Sangiorgi discutindo "problemas de estruturas". A Editora encerra a apresentação da nova edição dizendo estar "orgulhosa de permanecer na vanguarda editorial brasileira, oferecendo aos nossos estudantes livros didáticos de alto nível que hoje já se destacam no mercado internacional." A assinatura da empresa é acompanhada do slogan: "Companhia Editora Nacional - líder e pioneira na renovação de livros didáticos no Brasil."

O texto de Sangiorgi, colocado logo após o da Editora, é dirigido aos professores e reproduz a Apresentação do novo volume 1, sob o título Palavra ao Professor. Nele, inicialmente, Sangiorgi faz um balanço bastante positivo de quatro anos de matemática moderna, divulgados por meio dos quatro títulos já publicados de sua coleção: com a publicação, em 1967, do Volume 4, da Matemática, Curso Moderno, de nossa autoria, dentro da filosofia preconizada desde o lançamento do Volume 1 (1963), podemos dizer que foram alcançados, depois de quatro anos de continuado e intenso trabalho, os principais objetivos perseguidos na reformulação do ensino da Matemática na escola secundária brasileira.

Depois de discorrer sobre como a Matemática Moderna vem atraindo mais e mais os alunos, Sangiorgi aproveita para realizar um contraponto da matemática moderna com a matemática clássica: enquanto a chamada Matemática Clássica resolvia um determinado problema com 'fórmulas prontas', a Matemática Moderna criando estruturas gerais colocou-se num ponto de vista bem mais amplo, deixando a solução dos problemas particulares como exercício de suas poderosas ferramentas.

Sangiorgi também justifica e explicita as pequenas modificações que foram realizadas no Volume 1 de sua coleção para o ensino de Matemática Moderna, ponderando ser "natural que depois de uma vivência contínua no ciclo ginasial (4

Rev. Diálogo Educ., Curitiba, v. 8, n. 25, p. 583-613, set./dez. 2008 
Osvaldo Sangiorgi e o movimento da matemática moderna no Brasil 609

anos), que se faça revisão e remanejamento de alguns assuntos tratados pelos quatro livros". A alteração e remanejamento de alguns temas, segundo Sangiorgi, estavam ligados à própria introdução da matemática moderna no ensino primário, o que permitiu aos alunos desse nível escolar, já ter aprendido as suas primeiras noções, possibilitando alterações na programação da primeira série ginasial:

Desde que alguns dos seis primeiros itens, dos 24 que compõem os "Assuntos Mínimos para um Moderno Programa de Matemática", expostos na 1ª edição (1963), do Volume 1, começaram a ser introduzidos, a partir de 1965, também nos Cursos de Admissão, o ensino primário passou a desfrutar das mesmas idéias unificadoras da Matemática ensinada na escola secundária, conseguindo a seguir, por intermédio da linguagem dos conjuntos motivar grande número de alunos dessas escolas primárias. (SANGIORGI, 1968, p. 4).

Desde os anos 50, Sangiorgi participa de bancas dos exames de admissão, verdadeiro vestibular, oral e escrito, a que se submetem os alunos que terminam o ensino primário, e rumam em direção ao ginásio. Sangiorgi, ainda, é um dos responsáveis pela elaboração dos exames e do programa a ser cobrado nas provas. Sua referência didática para tais exames, assim, constitui-se como decisiva para o sucesso nessas avaliações. Desse modo, um dos livros mais vendidos pela Companhia Editora Nacional foi o Programa de Admissão. Para que se tenha uma idéia, em 1968, a Editora publica a 18a. edição da obra, com tiragem de cerca de 250 mil exemplares. O livro, organizado por grandes autores de obras didáticas das diferentes disciplinas, como Aroldo de Azevedo (Geografia); Cretella Júnior (Português); Joaquim Silva e Arruda Penteado (História) dentre outros, tem Osvaldo Sangiorgi como autor da Matemática.

Como menciona Sangiorgi, a partir de 1965, elementos de Matemática Moderna começam a fazer parte da programação a ser avaliada pelos exames de admissão ao ginásio. É também pela ação desse professor que o ensino primário incorporou a programação moderna da Matemática. Ela tem referência no livro destinado aos exames de admissão, que por esse tempo, estampa na capa da obra, com grande destaque, os dizeres: "Programa de Admissão - NOVO com Matemática Moderna". ${ }^{19}$

19 Uma das figuras importantes do Movimento da Matemática Moderna no ensino primário, a professora Anna Franchi, em sua tese de doutoramento, constata que tópicos inteiros do volume 1, do livro de Sangiorgi, foram transportados para as séries iniciais e, também, para os exames de admissão. FRANCHI, A. Compreensão das situaçōes multiplicativas elementares. 1995. 232 f. Tese (Doutorado em Educação) - Pontifícia Universidade Católica de São Paulo, São Paulo, 1995.

Rev. Diálogo Educ., Curitiba, v. 8, n. 25, p. 583-613, set./dez. 2008 


\section{CONSIDERAÇÕES FINAIS}

Há cem atrás é lançado o primeiro movimento que busca internacionalizar uma proposta de ensino de matemática. Em Roma, em 1908, de forma inédita, matemáticos voltam suas preocupações para o ensino de matemática. É criada uma comissão, encabeçada pelo notável Felix Klein. A Matemática parece se prestar mais do que qualquer outra disciplina, a estudos comparativos. Afinal, ela está presente nos currículos escolares do mundo todo. São realizados inquéritos e a quantidade de relatórios sobre o ensino de matemática nos diferentes países é enorme. Por fim, todo o trabalho comparativo revelou-se como uma estratégia para internacionalizar propostas originadas das ações do próprio Klein, na Prússia. O resultado do apoio conseguido para essa internacionalização resultou em formas absolutamente diferentes do modelo curricular prescrito. ${ }^{20}$ É possível dizer sobre isso, o que hoje parece óbvio: Matemática também é cultura. Ou, ainda: o ensino de matemática também é cultura! O que leva a lembrar da síntese produzida pela historiadora da educação Marta Chagas de Carvalho, a partir de estudos dos historiadores Roger Chartier e Michel De Certeau:

A impossibilidade de determinar os usos de objetos culturais a partir exclusivamente dos usos visados ou prescritos, inscritos na sua materialidade de objetos, não exibe apenas a dificuldade conceitual maior de uma história cultural. Ela configura também instigantes possibilidades de percurso, estendendo o campo dessa modalidade de história cultural. Contrapesando os limites impostos à determinação inequívoca dos usos de modelos, o hiato entre os usos prescritos e usos efetivos abre um enorme campo de investigação sobre a circulação temporal e espacial de objetos culturais. Essa circulação possibilita usos discrepantes dos previstos na situação cultural que presidiu a sua produção, abrindo um vasto campo para estudos sobre práticas diferenciadas e contrastantes de apropriação dos modelos culturais neles materialmente inscritos. (CARVALHO, 2006, p. 141).

20 Uma análise dessas conclusões, no âmbito internacional, pode ser lida em BELHOSTE, B. et. al. Les sciences au lycée: um siècle de reformes des mathématiques et de la physique en France et à l'étranger. Paris: INRP, 1996. e, ainda, no Brasil, em VALENTE, W. R. (Org.). Osvaldo Sangiorgi: um professor moderno. São Paulo: Annablume/CNPq (no prelo).

Rev. Diálogo Educ., Curitiba, v. 8, n. 25, p. 583-613, set./dez. 2008 
Osvaldo Sangiorgi e o movimento da matemática moderna no Brasil 611

No entanto, cinquenta anos depois da criação da Comissão Internacional, nem o lema "Matemática também é cultura", nem tampouco o "O ensino de matemática também é cultura" parecem fazer história. A emblemática obra L'enseignement des mathématiques, desde o seu Préface já anuncia:

O problema do ensino de matemática se coloca hoje em termos que ultrapassam fronteiras. As diferenças devidas às culturas são menos importantes que as semelhanças resultantes da estrutura da ciência e do pensamento matemático. (PIAGET et. al. 1955, p. 8).

Mas, o Movimento da Matemática Moderna resultou múltiplo, aqui e noutros países. Entre nós, o professor Osvaldo Sangiorgi, tem papel de destaque. A seu tempo, com suas ferramentas de apropriação, sua leitura do contexto educacional, seu posicionamento de grande autor de livros didáticos de matemática, dentre tantos outros condicionamentos, cabe-lhe a tarefa pioneira de criar estratégias para que as discussões internacionais sobre o ensino de matemática ecoem também no Brasil. Nas salas de aula, no cotidiano escolar das décadas de 60 a 80, podem ser lidas as táticas aí desenvolvidas para receber a "proposta osvaldiana" para os ginásios. Essa história, no entanto, ainda está para ser produzida.

\section{REFERÊNCIAS}

BELHOSTE, B. et al. Les sciences au lycée: um siècle de reformes des mathématiques et de la physique en France et à l'étranger. Paris: INRP, 1996.

BETH, E. Réflexions sur l'organisation et la méthode de l'enseignement mathématique. In: PIAGET, J. et al. L'enseignement des mathématiques. Suisse: Delachaux \& Niestlé S. A., 1955. p. 45-46.

BETH, E. W. Les fondements logiques des mathématiques. Paris: Gauthier-Villars, 1955.

BORGES, R. A. S. A matemática moderna no Brasil: as primeiras experiências e propostas de seu ensino. 2005. 196 f. Dissertação (Mestrado em Educação Matemática) - Programa de Estudos PósGraduados em Educação Matemática da PUC-SP, São Paulo, 2005.

BÚRIGO, E. Z. Movimento da Matemática Moderna no Brasil: estudo da ação e do pensamento de educadores matemáticos nos anos 60. 1989. 285 f. Dissertação (Mestrado em Educação) - Universidade Federal do Rio Grande do Sul, Porto Alegre-RS, 1989.

Rev. Diálogo Educ., Curitiba, v. 8, n. 25, p. 583-613, set./dez. 2008 
CARVALHO, M. M. C. Livros e revistas para professores: configuração material do impresso e circulação internacional de modelos pedagógicos. In: PINTASSILGO, J. et al. História da escola em Portugal e no Brasil: circulação e apropriação de modelos culturais. Lisboa: Colibri, 2006, p. 141-175.

CHOQUET, G. Sur l'enseignement de la géométrie élémentaire. In: PIAGET, J. etal. L'enseignement des mathématiques. Suisse: Delachaux \& Niestlé S. A., 1955. p. 75-76.

CONGRESSO NACIONAL DE ENSINO DA MATEMÁTICA, 2., Porto Alegre. Anais... Porto Alegre, RS: Gráfica da Universidade do Rio Grande do Sul, [1957], 1959a. p. 272-399.

CONGRESSO BRASILEIRO DO ENSINO DA MATEMÁTICA, 3., 1959, Rio de Janeiro. Anais... Rio de Janeiro: CADES-MEC, 1959b. p. 214-225.

D'AMBROSIO, B. The dynamics and consequences of the modern mathematics reform movement for Brazilian mathematics education. 1987. 298 f. Thesis (Doctor in Education) - Indiana University, Estados Unidos, 1987.

DIEUDONNÉ, J. L'abstraction en mathématique et l'évolution de l'algèbre. In: PIAGET, J. et al. L'enseignement des mathématiques. Suisse: Delachaux \& Niestlé S. A., 1955. p. 48-61.

FRANCHI, A. Compreensão das situações multiplicativas elementares. 1995. 232 f. Tese (Doutoramento em Educação) Pontifícia Universidade Católica de São Paulo, São Paulo, 1995.

GEEM. Matemática moderna para o ensino secundário. São Paulo: USP, 1962.

GUIMARÃES, H. M. Por uma matemática nova nas escolas secundárias: perspectivas e orientações curriculares da matemática moderna. In: MATOS, J. M.; VALENTE, W. R. (Org.). A matemática moderna nas escolas do Brasil e de Portugal: primeiros estudos. São Paulo: Da Vinci / CAPES-GRICES, 2007, p. 21-45.

GUIMARÃES, L. As cores na mídia: a organização da cor-informação no jornalismo. São Paulo: Annablume, 2003.

INSTITUTO BRASILEIRO DE EDUCAÇÃO, CIÊNCIA E CULTURA. Notícias do IBECC. São Paulo: IBECC, 1962.

Rev. Diálogo Educ., Curitiba, v. 8, n. 25, p. 583-613, set./dez. 2008 
Osvaldo Sangiorgi e o movimento da matemática moderna no Brasil 613

LICHNEROWICZ, A. Introduction de l'esprit de l'algèbre moderne dans l'algèbre et la géométrie élémentaire. In: PIAGET, J. et al. L'enseignement des mathématiques. Suisse: Delachaux \& Niestlé S. A., 1955. p. 66-74.

NAKASHIMA, M. O papel da imprensa no Movimento da Matemática Moderna. 2007. 205 f. Dissertação (Mestrado em Educação Matemática) - Programa de Estudos Pós-Graduados em Educação Matemática da PUC-SP, São Paulo, 2007.

PIAGET, J. et al. L'enseignement des mathématiques. Suisse: Delachaux \& Niestlé S. A., 1955.

SANGIORGI, O. Cursos de verão. Atualidades pedagógicas. São Paulo: Nacional. 1960. p. 7-12.

Matemática: curso moderno. São Paulo: Nacional, 1963. v. 1.

VALENTE, W. R. (Org.). Osvaldo Sangiorgi: um professor moderno. São Paulo: Annablume/CNPq (no prelo).

Euclides Roxo e a modernização do ensino da matemática no Brasil. Brasília: UnB, 2004.

Recebido: 02/04/2008

Received: 04/02/2008

Aprovado: 01/07/2008

Approved: 07/01/2008

Rev. Diálogo Educ., Curitiba, v. 8, n. 25, p. 583-613, set./dez. 2008 